Draft: 10-11-10 [penultimate version]

\title{
On Intellectualism in Epistemology
}

STEPHEN R. GRIMM

According to 'orthodox' epistemology, it has recently been said, whether or not a true belief amounts to knowledge depends exclusively on truth-related factors: for example, on whether the true belief was formed in a reliable way, or was supported by good evidence, and so on. ${ }^{1}$ Jason Stanley (2005) refers to this as the 'intellectualist' component of orthodox epistemology, and Jeremy Fantl and Matthew McGrath (2007 and forthcoming; cf. 2002) describe it as orthodox epistemology's commitment to a 'purely epistemic' account of knowledge-that is, an account of knowledge where only truth-related factors figure in whether or not a person knows. ${ }^{2}$

If Stanley, Fantl, and McGrath are correct, however, this 'intellectualist' component of orthodox epistemology can no longer be sustained; indeed, given its apparent centrality to orthodox epistemology, it seems unlikely that orthodox or traditional epistemology as a whole can be sustained. Why? Because on their view whether or not a true belief amounts to knowledge essentially depends on certain non-truth related factors. In particular, on their view whether or not a given true belief amounts to knowledge depends on the practical cost of being wrong about the subject at issue, where (in Stanley's words) 'Someone's practical investment in the truth or falsity of her belief is completely irrelevant to truthconduciveness in any sense' (Stanley 2005, p. 2).

\footnotetext{
${ }^{1}$ The claim that this amounts to 'orthodoxy' in epistemology is Stanley's (2005, p. 2); Fantl and McGrath (2007, p. 558) refer to it as the 'traditional' view in epistemology.

${ }^{2}$ Although he is not as insistent about claiming a break with orthodoxy, John Hawthorne too, in his book Knowledge and Lotteries, argues that whether a true belief amounts to knowledge depends on factors over and above the sort "traditionally adverted to in accounts of knowledge-whether the subject believes the proposition, whether that proposition is true, whether the subject has good evidence, whether the subject is using a reliable method, and so on' (2004, p. 158).
} 
Borrowing Stanley's label and basic idea, and in keeping with similar thoughts by

Fantl and McGrath, we can think of intellectualism in the following terms:

Intellectualism: whether a true belief amounts to knowledge depends exclusively on truth-related factors. 3

If 'intellectualism' is an acceptable name for the thesis they are criticizing, for convenience I will refer to the position that they want to defend under the name 'practicalism'. ${ }^{4}$ So understood, practicalism is the view that whether a given true belief amounts to knowledge depends on the satisfaction of certain non-truth related factors-in particular (it seems), it depends on whether or not the belief is appropriately responsive to the practical cost of being wrong.

If its advocates are to be believed, practicalism is therefore meant to be a radical departure from traditional epistemology. If the language of orthodoxy is indeed apt, it is supposed to be an epistemological heresy of some kind. One thing I would like to do in the first part of this paper, however, is to question how radical this new approach really is. More exactly, I want to argue that the view's apparent radicalism stems from an ambiguity in the notion of what it means for a belief to 'depend' on non-truth-connected factors. Once the notion of dependence is disambiguated, I will suggest, practicalism should start to look less like a heresy and more like a sort of discovery or clarification.

In the remainder of the paper I will then take a more critical turn and argue that even if, as a matter of fact, traditional epistemology has accepted intellectualism in both of the forms that I identify, this is a mistake on the part of the tradition. At least one strain of

\footnotetext{
3 In Fantl and McGrath's words: 'According to received tradition in epistemology, whether a true belief amounts to knowledge depends only on purely epistemic factors-factors that are appropriately truth related' (2007, p. 558). In Stanley's words: 'I will call the thesis that knowledge does not depend upon practical facts intellectualism' (2005, p. 6); putting this thought together with the claim (quoted above) that 'Someone's practical investment in the truth or falsity of her belief is completely irrelevant to truthconduciveness in any sense' (2005, p. 2), seems to give us the same thesis.

4 Since Fantl and McGrath at least explicitly embrace what they-following Jonathan Kvanvig's suggestion on the blog Certain Doubts-call a 'pragmatic encroachment on epistemology,' it is therefore tempting to refer of their view as a kind of pragmatism. That is a term with too many connotations built in, however.
} 
intellectualism should be rejected and its practicalist counterpart should be accepted instead.

\section{The Argument for Practicalism}

The argument for practicalism typically begins with a comparison of so-called 'Low Stakes' versus 'High Stakes' cases. These cases should by now be quite familiar, but it is worth having a concrete example in front of us, if for no other reason than that the details of these cases often change, and the details often matter.

So suppose that Hannah believes that her local bank will be open on Saturday, and this on the basis of her knowledge that the bank was open when she deposited some checks two Saturdays prior. 5 Suppose as well that the bank will, as a matter of fact, be open on Saturday. Does her belief amount to knowledge? According to practicalists, in order to answer this question we first need to take into account how much is at issue; in other words, we first need to factor in the practical stakes.

To take a Low Stakes version of the case, suppose that there are no urgent practical reasons for us, as third party evaluators, to make it to the bank on Saturday, and that Hannah reports her belief to us, along with her evidence for the belief. Under these circumstances, it seems that most of us would judge that Hannah does (in fact) know. Intuitively, her evidence seems quite good-good enough to know.

Compare this, however, with a High Stakes version of the case, where whether or not the bank is open matters a great deal to us. (Perhaps, if the bank is closed we will not be able to deposit a certain important check.) Hannah again reports her belief, along with her

\footnotetext{
5 'Bank cases' of this sort were first introduced by DeRose (1992). Other examples of High Stakes/Low Stakes cases of this sort include Stewart Cohen's (1999; 2008) airport case and Fantl and McGrath's (2002) train case. Stanley (2005) follows DeRose in focusing on bank cases. It is worth noting as well that there are considerably older cases in the literature where high practical stakes seem to affect whether one knows; W. C. K. Clifford's (1879) 'ship owner case,' in which lives will be lost if the owner is mistaken about whether his ship is seaworthy, is a particularly clear example.
} 
evidence. Does she know? It seems fair to say that most are inclined here to judge that she does not know; or, at least, the inclination to judge that she fails to know seems much more powerful in this case than in the previous one.

I noted above that these Low Stakes/High Stakes cases are presented in various ways in the literature. Sometimes, for example, the subject being evaluated actually uses the word 'know' and sometimes she does not; sometimes the practical stakes are the subject's while sometimes (as in this case) they are the evaluator's; and so on. For now, however, the only point I want to emphasize is that as I have described things our judgments in the two cases are examples of what we might call first-order epistemological judgments. In other words, as third party evaluators, what we are doing is judging whether or not Hannah's belief amounts to knowledge, first in the one case and then in the other; we are thus not making judgments, for example, about the truth value of sentences that use epistemic predicates to attribute or deny epistemic properties. ${ }^{6}$ In our case above, Hannah never said anything about 'knows'-she simply reported her belief, a belief that in one instance seemed to amount to knowledge, and in another instance, to fall short.

But what moral should we draw from these cases? What practicalists suggest is that since in both cases the 'truth-connected factors' are held fixed (not just the truth value of the proposition believed but also, in some straightforward sense, the strength of Hannah's epistemic position), then the most natural way to explain the difference in knowledge in these cases is in terms of the difference in the practical costs of being wrong, where the practical costs of being wrong do not look like obviously 'truth-connected' factors at all.

\footnotetext{
${ }^{6}$ For example, it is not a claim that someone's utterance of the sentence ' $\mathrm{S}$ knows that $\mathrm{p}$ ' is false. These are more naturally thought of as meta-linguistic judgments than first-order epistemological judgments. Note that my claim here is not that these two sorts of judgments are not closely related; indeed, it would be peculiar for someone to assent to the one claim but not the other. Since it seems possible for them to come apart, however (see, for example, Sosa 2000), for simplicity I will focus on the first-order judgments.
} 
Now, at this point one might try to defend intellectualism-and hence, it seems, orthodox epistemology as a whole-by raising doubts about our judgments in these cases. Perhaps, it might be said, Hannah either knows or fails to know in both versions of the case; if we think otherwise, that is for pragmatic rather than (broadly speaking) semantic reasons.7 In what follows, however, for the most part I will not question the typical judgments about these cases described above; in fact, not only do I think that these judgments should by and large be taken at face value, but (as I will argue later in Section 6) I think that views that discount the role of practical considerations in knowledge encounter a variety of critical problems. One question we need to ask to begin with, however, is whether these judgments really tell against traditional, truth-connected epistemology in the way that practicalists have claimed. In my view, the lesson that these cases have to teach is a different one.

To see this we can start with an initial worry about the practicalist interpretation of the bank cases (and their cousins), and then try to clarify some of the issues that lie behind the initial worry.

Consider then Hannah's belief in the High Stakes case again. Why does her belief, true though it may be, not amount to knowledge? As we have already in effect noted, one natural response here is surely: because her evidence was not good enough. Alternatively, the answer might be: because her belief was in some sense too accidental; in some sense, it was not secure enough. But it seems clear that failures of this kind are truth-connected failures: they are failures of evidence, or failures of safety, and so on. But if that is right, then contra Stanley it does not seem to be the case that 'Someone's practical investment in the truth or falsity of her belief is completely irrelevant to truth-conduciveness in any sense';

\footnotetext{
7 Duncan Pritchard (2006), in his review of Stanley's book, suggests a response along these lines. Other appeals to conversational propriety in order to explain cases in this way include Patrick Rysiew (2001), Allan Hazlett (2009), and John Turri (2010.)
} 
instead, it seems that when a difference in practical stakes makes a difference to whether one knows, it necessarily makes a difference along traditional, truth-connected lines.

If this point is not clear enough, here's another way to illustrate the worry. Suppose that in both the Low Stakes and the High Stakes version of the case Hannah's evidence is extraordinarily good: she'd been to the bank every Saturday for the last ten years, was alert to changes in the schedule, had just phoned the bank to double-check, and so on-make her evidence as overwhelming as you like. And now suppose that the difference in stakes between the two cases varies dramatically: while virtually nothing hangs on the first case, lives are at stake in the second. Does she fail to know in this High Stakes case? Given the quality of her evidence, presumably not. True, the stakes were dramatically raised; but her evidence was good enough to match the stakes. It therefore seems that when a difference in practical stakes leads to a difference in knowledge, the difference in knowledge only occurs because the strength of the person's evidence (reliability, etc.) has, in some sense, failed to keep pace. In other words, the failure to know always seems due, at least in part, to an epistemic (truth-connected) lack of this kind.

At first blush, it therefore seems that when practical stakes matter to knowledge, they only matter insofar as they impact traditional truth-related factors-factors such as the quality of one's evidence, or one's reliability, and so on. Put another way, what this suggests is that a failure of knowledge is never simply due to a difference in practical stakes; instead, when a failure occurs it always seems to be because one has also come up short with respect to one of these traditional, truth-connected factors.

\section{The Race Goal}

We can now see that although something seems right about the practicalist interpretation of the previous cases-namely, that knowledge seems harder to come by 
when the practical stakes go up-something seems conspicuously wrong as well. In particular, it seems wrong to conclude, as practicalists such as Stanley conclude, that the difference in stakes is 'completely irrelevant' to the sort of traditional truth-related factors that we typically associate with knowledge.

To try to move beyond this impasse, in this section I will look at another case where the same sort of ambivalence seems to be in play. In the following section I will then consider what this comparison might teach us about our questions concerning knowledge.

So suppose, then, that Miller and Smith are amateur runners, gearing up for their town's annual Race Day. They both train together for several weeks, their muscles and joints are equally limber, and their cardiovascular conditioning is more or less identical. Focusing especially on their level of cardiovascular conditioning, we might therefore say that they are equally fit. Thus, as Miller goes with respect to fitness, so goes Smith.

On Race Day, however, whereas Miller enters the $5 \mathrm{~K}$ race, Smith tries for the $15 \mathrm{~K}$. And while Miller finishes his race easily, unfortunately at about the $11 \mathrm{~K}$ mark of his race, Smith begins to break down. Smith's breathing becomes labored, his joints throb; in short, he runs out of gas. While Smith is as fit as Miller, and while we might even say that he simply is fit, ${ }^{8}$ he is not fit enough to finish the $15 \mathrm{~K}$.

With this in mind, and looking at Miller's and Smith's respective performances, we can now ask a variety of questions. For example, we might ask:

Q1. Why did Smith fail to finish the race?

And I take it that here a perfectly respectable answer would be something along the lines of:

A1. Because he wasn't fit enough. Or perhaps: because he ran out of gas.

Or again, we might ask:

8 When we say someone simply is fit, what we seem to mean is that are fit enough to perform a variety of physically demanding tasks: for example, fit enough to jog a mile or two, to hike a small hill, and so on. 
Q2. Why did Miller succeed in finishing the race?

And likewise, a good answer would seem to be:

A2. Because he was fit enough. Or perhaps: because he had plenty left in the tank.

In short, it seems that when we ask what we might think of as 'straightforward' explanationseeking questions of the Q1 and Q2 variety, the answers will typically advert to the usual sorts of factors: namely, someone's level of fitness, the durability of his or her joints, and so on. 9

In addition to straightforward questions, however, we can also ask contrastive questions of the following sort: ${ }^{10}$

Q3. Why did Miller, rather than Smith, finish his (Miller's) race?

And here it seems natural to say that Miller finished his race, while Smith did not, because Miller ran a $5 \mathrm{~K}$ race rather than a $15 \mathrm{~K}$; alternatively, that Smith failed to finish because he ran the $15 \mathrm{~K}$ rather than the $5 \mathrm{~K} \cdot{ }^{11}$

For our purposes, the important point is that what these different questions help to reveal is that finishing a race depends on two very different sorts of factors. On the one hand, it depends on what we might think of as 'goal realization' factors: in this case, factors

\footnotetext{
${ }_{9}$ Although depending on the case, still other factors (having to do with diet, for instance) might enter into an explanation.

${ }^{10}$ In emphasizing the contrastive nature of the questions that follow, I do not mean to imply that the previous questions were not contrastive: there may have, for example, been some hidden contrast embedded in the previous questions.

${ }^{11}$ Although, again, depending on the case one might advert not just to the distance but also (say) to the slope of course, or to its treacherousness, or perhaps even to the weather conditions. For most factors of this sort, it seems natural to think of them as bearing on the "goal-threshold" dimension of dependence, because they help to determine how much fitness etc. is needed to finish the race: thus, one will need a certain amount of fitness to finish a $5 \mathrm{~K}$ on a mostly flat course, while one will need a different amount to finish a $5 \mathrm{~K}$ on a course with steep hills (and similarly for a $5 \mathrm{~K}$ in a thunderstorm as opposed to a sunny day, etc.). One further issue is that, depending on how one thinks of dependence, finishing the race goal might also seem to depend on factors such as the absence of nerve gas, on the fact that the sun did not suddenly collapse, and so on. Here it seems most natural to think of these factors as something like enabling conditions rather than proper elements of the explanation, but I grant that it is a tricky business to try to distinguish the two (for a sophisticated attempt see Menzies 2004). Thanks to the Editor for his help in bringing out some of the subtleties here.
} 
such as fitness, durability, and so on..$^{12}$ On the other hand, finishing a race depends on what we might think of as 'goal threshold' factors as well: in this case, factors having to do with the distance of the race. We can try to express these differences, a bit crudely, in a chart along the following lines:

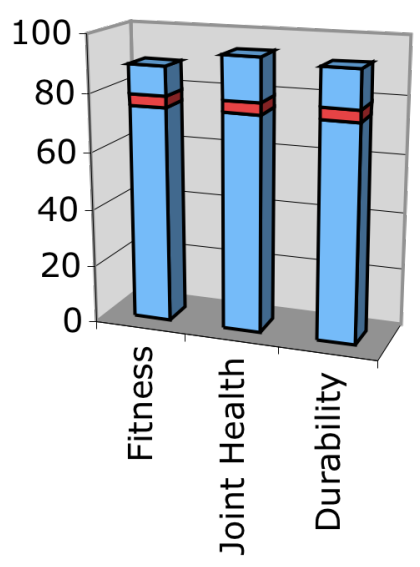

I say that this chart is a bit crude, because in reality there would be more of a dynamic relationship among the vertical factors than the chart (or my chart-making skills) suggests: thus severe problems with one's joints, for example, could destroy one's ability to finish a race no matter how superb one's cardiovascular conditioning might be. Crudeness aside, however, the basic point I want to bring into focus is not just that the sorts of dependence at issue here are quite different, but that when changes along the 'goal threshold' dimension (here, changes in the distance of the race, marked by the horizontal stripe) make a difference, this is apparently always in relation to the usual sorts of 'goal realization' categories: in other words, in relation to fitness, or joint health, and so on-that is to say, in relation to the vertical categories depicted on the chart. More colloquially, what

\footnotetext{
12 An alternative name for these might be "goal-satisfaction" factors. It is hard to think of a name that applies perfectly here, but I hope these titles are clear enough, especially once the comparison with the threshold dimension is made explicit.
} 
the factors related to the threshold determine is how much of a particular goal-realization factor is needed, if one is in fact to realize one's goal: in this case, if one is to finish the race.

\section{The Knowledge Goal}

In this section I will suggest that many of these claims about the race case can be applied straightforwardly to the case of knowledge. Indeed, the comparisons seem clear enough that I will review them relatively quickly. In the following section, I will then spend more time considering what all of this has to teach us about the fate of intellectualism, and hence of 'orthodox' or truth-connected epistemology more generally.

One basic point of comparison to begin with is that, analogous to the goal of finishing the race, it is plausible to think of knowledge too as a kind of goal-a goal, moreover, that is tied to various sorts of factors. Ernest Sosa puts this idea in the following way:

Our concept of knowledge involves various dimensions each admitting a threshold: (a) 'belief': how sure must one be? (b) 'justification': how much rational support is required for one's belief? (c) 'reliability': how reliable are one's operative sources or faculties? (d) 'safety': how easily might one have been wrong; how remote is any belief/fact mismatch? (Sosa 2000, p. 6)

If we wanted to express these factors (or 'dimensions') along the lines of the previous chart, moreover, and if (to maintain continuity with the previous discussion) we wanted to add in an additional truth-connected factor such as 'evidence,' they might look something like this: 


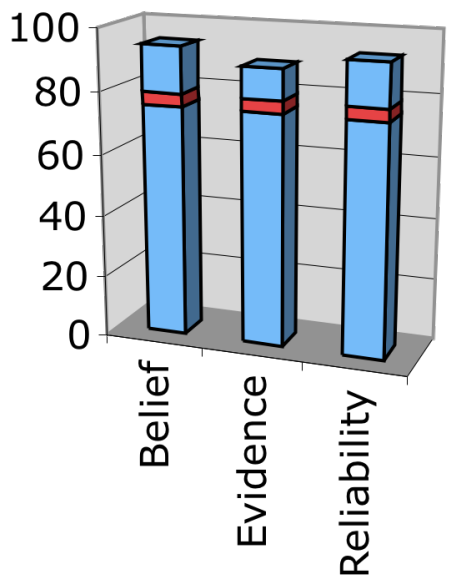

Once again, this chart is just a beginning. Thus, one might think that the best way to think about the notion of reliability is in terms of the notion of safety; or one might think that safety itself is purely a function of one's evidence; or instead that safety depends on certain non-evidential factors. And so on. But I hope this is a start, at any rate.

Now, as Sosa also suggests, it is natural to think not just that these are the factors that matter with respect to knowledge, but that these factors are tied to various thresholds. In other words, it is natural to think not just that (for example) safety matters to knowledge, or that evidence matters, but that for a particular belief to amount to knowledge it needs to be safe enough, or that for a belief to amount to knowledge one's evidence must be adequate or sufficient, where the notions of adequacy or sufficiency again seem to be thresholdrelated notions. What's more, if we think that the threshold is capable of variation from case to case, then what this suggests is that-just as we saw with the race goal before-while $\mathrm{S}$ might have the same evidence as $\mathrm{S}^{*}$, and while S's and $\mathrm{S}^{*}$ 's evidence might both be good (good simpliciter, as it were), S's evidence might nonetheless be good enough to satisfy the relevant threshold while $\mathrm{S}^{*}$ 's evidence might not be good enough. ${ }^{13}$

\footnotetext{
${ }^{13}$ Since the notion of having 'enough' evidence for knowledge is similar to Stewart Cohen's (1988; cf.
} 1999) proposal that one must have 'sufficient' evidence for knowledge, it is worth noting a few ways in 
In all of these ways, then, whether a particular belief amounts to knowledge seems to depend on a variety of factors, just as whether a particular runner finishes his or her race depends on a variety of factors. ${ }^{14}$ More importantly, the sort of factors that matter once again seem to matter along two quite different dimensions: roughly, along both 'goalrealization' and 'goal-threshold' dimensions, where the goal-threshold dimension has to do with factors that determine the nature of the thresholds to be satisfied, and the goalrealization dimension has to do with the factors that are relevant to satisfying the thresholds. Thus, just as a change in the distance of the race impacts how fit one needs to be to finish the race, so too, it seems, a change in the thresholds relevant to knowledge will affect how good one's evidence needs to be, or how reliable one needs to be, if one's belief is to amount to knowledge.

\section{Intellectualism and Orthodox Epistemology}

As we turn to ask what the previous discussion has to do with the status of ‘intellectualism’-and hence, apparently, of orthodox epistemology more generally-we can now make a few points.

First, it is now possible to see that our original intellectualist thesis can be thought of in a few different ways, depending (for lack of a better word) on how the concept of

which our proposals differ. The first difference is that while Cohen formulates his view as a metalinguistic thesis, I have pitched my claims at the first-order epistemological level. Another difference arises from Cohen's claim that our evidence has to be sufficient to rule out error possibilities that have been made 'salient'-either in conversation or through our own reflection. By my lights, however, the sort of salience mechanisms that Cohen mentions are not sufficient by themselves to raise thresholds. As Hawthorne notes (2004, p. 64), if these were indeed the relevant mechanisms, then it seems like we would lose our knowledge that we have hands every time, say, we watched the Matrix. But this doesn't seem to be the case. On my view, the crucial threshold-raising mechanism is not conversational or reflective salience but rather a change in recognized practical stakes; where this is absent (as it arguably is in the Matrix case) thresholds fail to rise.

14 That said, it is worth pointing that the parallel between the two cases is not exact. A factor such as joint health, for instance, can be properly understood without any reference to the goal of finishing races, whereas a factor such as evidence cannot, I think, be properly understood apart from its connection to the truth. (Thus, for one piece of evidence to be better than another, it seems, just is for it to be a better indication of the truth of the matter than the other piece. The way in which betterness in joint health bears on betterness in finishing races is more indirect.) 
dependence is itself understood. Recall that we earlier understood intellectualism as

follows:

Intellectualism: whether a true belief amounts to knowledge depends exclusively on truth-related factors.

But now in light of the fact that there seem to be various types of dependence at issue when

it comes to knowledge, this gives us at least two different ways of thinking about

intellectualism, as follows:

Realizer intellectualism: whether a true belief amounts to knowledge depends, in a goal-realization sense, exclusively on truth-related factors. ${ }^{15}$

Threshold intellectualism: whether a true belief amounts to knowledge depends, in a goal-threshold sense, exclusively on truth-related factors; alternatively, the various thresholds relevant to knowledge are determined exclusively by our purely epistemic (rather than our practical) goals and concerns. ${ }^{16}$

Plainly enough, realizer intellectualism is a thesis about the goal-realization dimension of dependence; it says that the only sorts of factors that matter to whether one knows, or to whether the knowledge goal is realized, are truth-connected factors-factors such as evidence, safety, and so on. Threshold intellectualism, by contrast, is a thesis about the goalthreshold dimension of dependence; it says that where the threshold related to (say) adequate evidence or sufficient evidence or good enough evidence is set is determined

15 There are some subtleties here that are worth noting. For example, if one accepts certain higher-order conditions on knowledge-such as that one have reflective awareness of the reliability of one's belief forming mechanisms, or that one be in a position to know that one knows (i.e. the KK principle)-then perhaps knowledge will depend on certain factors, in addition to true belief, which are not straightforwardly truth-related. For example, would this sort of reflective awareness really be a 'truthrelated' factor? Maybe, because the goal of one's awareness is a truth-connected factor (like reliability); but not obviously. At the very least, if one accepts higher-order conditions on knowledge, then factors will come into the picture that are not as straightforwardly truth-connected as factors such as reliability and evidence are. Thanks for an anonymous referee for drawing my attention to this point.

${ }^{16}$ What I offer here after the 'alternatively' is meant to capture the sort of idea we find in Jonathan Kvanvig's defense of the 'purely theoretical point of view'-where, in his words, the purely theoretical point of view is 'a point of view abstracting away from other purposes such as purposes which are practical, moral, aesthetical, religious, or political in nature' (Kvanvig 2009, p. 346; cf. Kvanvig 2008, pp. 201-202). I take it, then, that for philosophers such as Kvanvig the 'purely theoretical point of view' is one which evaluates beliefs only in the light of our 'purely theoretical' or 'purely epistemic' goals and concerns, rather than in the light of our non-purely theoretical goals and concerns. Just how to think about these purely theoretical (or epistemic) goals and concerns is a topic I will return to in Section 6. 
exclusively by our purely epistemic goals and concerns, rather than (in addition, or alternatively) by our practical goals and concerns.

And now we can ask: where does 'orthodox epistemology' stand with respect to these claims? Is it committed to both? Neither? Just one? Naturally, one problem with trying to answer questions of this kind is that they take for granted that there is a kind of orthodoxy on these issues in the literature, and that is unlikely, at least if an orthodoxy is understood as a kind of consensus view. ${ }^{17}$ (Philosophers, after all, tend to disagree.) Another problem is that even if this sort of consensus did exist, actually showing that it exists would seem to be an endless task. Still, these reservations aside, I think a plausible case can be made that while epistemologists have by and large been firmly committed to realizer intellectualism they have by and large been noncommittal with respect to threshold intellectualism.

To help see this, recall again the earlier passage from Sosa, in which he claims that the concept of knowledge involves a variety of factors (or 'dimensions'), each admitting of a threshold. But now notice that although Sosa just mentions a few different factors with respect to which one might evaluate a belief, in reality there are countless more: for example, one might evaluate a belief with respect to the degree of psychological comfort it provides, or its likelihood of furthering one's career, or the degree to which it is apt to satisfy one's co-religionists, and so on..$^{18}$ We could locate factors of this sort on our earlier chart as follows:

\footnotetext{
${ }_{17}$ This problem is compounded if we think of the 'literature' as extending back to figures such as Descartes; on those grounds, the widespread contemporary commitment to fallibilism might well count as a kind of heresy. What I have in mind by the 'literature,' then-and more importantly, what I take it that Stanley, Fantl, and McGrath have in mind when they speak about the 'orthodox' view in epistemologybasically amounts to the post-Moore/Russell literature in epistemology. This is still vague, but I think it captures the basic idea the practicalists have in mind.

18 And an analogous factor in the race case might be something like the stylishness of the runner's gearthat is, a factor according to which the runner might score well or poorly, but which seems irrelevant to the goal of finishing the race.
} 


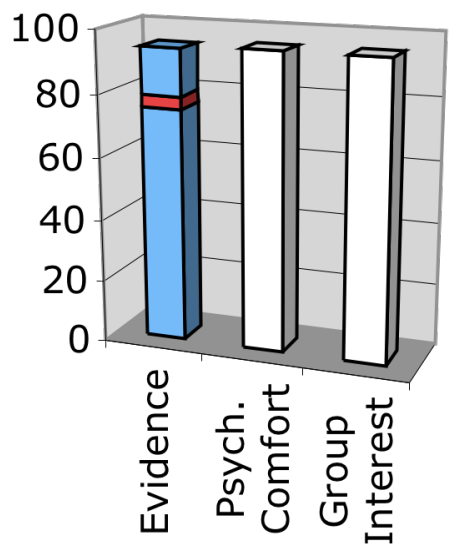

Now, given that there are these various dimensions along which a belief can be evaluated, it seems clear that what orthodoxy says is that none of these non-truth-connected factors are relevant to assessing whether a particular belief amounts to knowledge. ${ }^{19}$ What orthodoxy seems to clearly support, then, is realizer intellectualism; it says that the only factors that matter to knowledge are the truth-connected ones, and it rules out factors such as the likelihood that a particular belief will provide psychological comfort (or the like) as irrelevant to knowledge. Again, even though it would take an extended look at the literature actually to show this, I hope that the general thesis sounds familiar enough-and hence, I hope, traditional enough-to support the point.

The more controversial claim, I take it, is thus not that orthodox epistemology is committed to realizer intellectualism, but rather that is has been by and large noncommittal about threshold intellectualism. Now, to make the case that orthodox epistemology has been

\footnotetext{
19 Thus the familiar examples of, say, the hospital patient who believes, in the teeth of the evidence, that he will improve, or the mountain climber who believes, again against the evidence, that he will be able to jump the crevasse; what these examples are supposed to show is that however well these beliefs might score along certain practical or prudential measures, since they do not score well along truth-connected lines they are poor candidates for knowledge. Of course, it isn't necessarily the case that a concern for psychological comfort will come apart from a concern for the truth; thus, for example, many might find comfort only in the truth, and the possibility of error, likewise, is a source of discomfort. It is possible, however, that the two can come apart: the mother who would be distressed to learn that her son committed a crime is the classic example. Perhaps a better way to put the distinction, then, is between those factors which are essentially truth-connected and those which are not.
} 
noncommittal about some topic is perhaps even more ill-advised than to make the case that it has been positively inclined one way or another; again, to show this would require the sort of exhaustive search I will not attempt here. But once again I think a plausible case can be made.

For one thing, it is a common complaint against theories such as reliabilism that they are vague about what, exactly, determines how much reliability is needed for knowledge, ${ }^{20}$ and against relevant alternative theories that they are vague about what determines which alternatives, exactly, need to be ruled out by the evidence. In other words, if these complaints are apt, what these theories are vague about is the nature of the factors (or mechanisms) that determine where and how the various thresholds favored by these theories are actually set. ${ }^{21}$ The following passage from J. L. Austin, in which he argues that our evidence can be adequate for knowledge even if it fails to rule out every error possibility, suggests that this sort of complaint is not groundless:

Enough is enough: it doesn't mean everything. Enough means enough to show that (within reason, and for present intents and purposes) it "can't" be anything else, there is no room for alternative, competing description. It does not mean, for example, enough to show that it isn't a stuffed goldfinch. (Austin 1946, p. 52.)

\footnotetext{
${ }^{20}$ Laurence BonJour, for example, finds it striking that while reliabilists are content to say that reliability is required for knowledge, they fail to explain either how much reliability is required or how that level is actually determined: 'There is no very obvious way of answering this question, and the even more striking fact is that almost none of the advocates of the weak conception of knowledge [i.e. a reliabilist conception] have ever seriously tried to do so. Even more important, it is simply unclear what sort of basis or rationale there must be for fixing this level of justification in a non-arbitrary way.... This problem by itself calls into question whether any clearly motivated version of the supposed weak conception of knowledge even exists as an alternative to the strong conception' (BonJour 2002, p. 43).

${ }^{21}$ It is perhaps also worth noting that, in response to Fantl and McGrath's original (2002) claim that the practicalist cases make special trouble for evidentialism, Conee and Feldman (2004) insist that this objection rests on a confusion. As they explain things, evidentialism simply has nothing to say about whether the sort of justification needed for knowledge is subject to practical concerns; instead, the property of justification that they take to be relevant to evidentialism is concerned only with 'the epistemic justification that a person may have for believing a proposition' (p. 103). But, on their view, this 'do[es] not imply anything about how justification relates to knowledge. In particular, [it does] not imply that the strength of justification that is needed for knowledge is the same in all cases' (p. 103). According to Conee and Feldman, then, the evidentialist line is simply silent about the sort of justification that is relevant to knowledge; which is to say, apparently, that it is neutral with respect to threshold intellectualism.
} 
I say this passage suggests the complaint is not groundless, because while Austin is clearly within the orthodox camp in thinking that what matters for knowledge is having enough of a traditional-truth connected factor (such as evidence), he seems noncommittal about whether the sort of "present intents and purposes" that help to determine how much evidence is enough correspond to our purely epistemic intents and purposes, or to our practical intents and purposes, or to some combination of the two.

For another thing, it seems clear that the sorts of questions that have mainly occupied the attention of epistemologists (at least post-Gettier) have primarily been concerned with the realization dimension of dependence rather than with the threshold dimension: they have been questions for instance about whether it is good evidence that makes the difference between knowledge and true belief or whether instead it is reliability, or proper function, or some other property. ${ }^{22}$ Indeed, according to Sosa at least, the concern with how thresholds are set is not just new (and largely inspired by the literature on contextualism), but less epistemologically significant or interesting than the traditional questions about the realization dimension of dependence, which (again) were concerned with identifying the property or quality needed to transform true belief into knowledge, as opposed to how much of that property or quality was needed.23 Even if one disagrees (as I do) with Sosa about the lesser interest of the threshold question, if he is right then this

${ }^{22}$ Or, alternatively, if the concern was not knowledge but a property such as justification or rationality, then with what makes for that other property (coherence, or reflective endorsement, or something else). 23 "The new contextualism's distinctive contributions concern mainly our threshold-setting mechanisms. This issue is illuminated by such contextualism, whose light here is not dimmed even if, as I contend, the more important questions in epistemology concern rather the identity and nature of the relevant dimensions within which the thresholds must be set.... To me the more interesting point is that we do at least attain those lesser levels along the same dimension(s), whether or not the expression "knows" is in other contexts correctly applicable on that basis. Most interesting of all is this question: What are the appropriate dimensions along which a belief must be assessed in determining whether it qualifies as knowledge? What are the dimensions that we care about when we want our beliefs to give us knowledge, when we want to know things? Remarkably, none of those questions seems affected by the metalinguistic ascent of contextualism." Although Sosa puts this point in terms of what he takes to be the more "important" or "interesting" issue-rather than in terms of the more "traditional" or "orthodox" issue-I take it that his reference to the "new contextualism's distinctive contributions" is meant to suggest that these threshold questions were not a major concern (if they were a concern at all) in the earlier literature. 
would further support the claim that orthodox epistemology has no firm commitments one way or the other on this issue, simply because until recently it has not taken up the question in a sustained way.

Now, it might be objected at this point that the reason why the threshold question has not been taken up in a sustained way is because until recently it had simply been assumed-commonsensically, as it were-that the thresholds relevant to knowledge were exclusively determined by our purely epistemic goals and concerns. But I think what our earlier remarks about the two different dimensions of dependence helps to show is that threshold intellectualism, once properly isolated and articulated, does not exactly stand out as a commonsensical or intuitive or obvious view. Instead, once properly isolated it seems to stand out as a theoretically contentious view-at the very least, it seems fair to say that it stands out as a view with considerably less intuitive appeal than realizer intellectualism.

Suppose for the moment that this way of thinking about orthodox epistemology and its commitments is accurate, at any rate: namely, that while it is firmly committed to realizer intellectualism, it has by and large been noncommittal about threshold intellectualism. ${ }^{24}$ We can now ask in a more pointed way how exactly the practicalist cases bear on these apparent commitments.

First, then, do the High Stakes/Low Stakes cases of the sort we considered at the outset tell against orthodox epistemology's commitment to realizer intellectualism? Apparently not. As we saw earlier, when a shift in practical goals and concerns makes a

\footnotetext{
24 In noting that the claim about neutrality is a 'by and large' claim, one thing I do not want to overlook is earlier (traditional?) defenders of practicalism in the literature; see, for instance, Hookway (1990) and Owens (2000). As Josh Orozco reminds me, there is also some evidence in Locke at least that practical stakes both can and legitimately do bear on our judgments about knowledge (or positive epistemic status more generally). Locke writes: 'it is a very wrong and irrational way of proceeding, to venture a greater good for a less, upon uncertain guesses and before a due examination be made, proportionable to the weightiness of the matter, and the concernment it is to us not to mistake' (1689, p. 278); and again: 'where the assent one way or the other is of no importance to the interest of anyone ... there 'tis not strange that the mind should give itself up to the common opinion, or render itself to the first comer' $(1689, \mathrm{p} .717)$.
} 
difference, it only seems to make a difference with respect to how much of the relevant truth-connected property is needed, if a belief is to amount to knowledge. What the practicalist cases do not suggest is that scoring well on non-truth connected propertiesproperties having to do with advancing one's self-interest, for example-matters to knowledge. But then practicalism-or the view that whether a true belief amounts to knowledge depends on the satisfaction of certain non-truth related factors-seems entirely compatible with 'orthodox' or truth-connected epistemology, at least if the orthodoxy at issue is realizer intellectualism. What practicalism seems to be incompatible with is threshold intellectualism, because what practicalism is most charitably interpreted as saying is that the sort of thresholds relevant to knowledge are in fact fixed (at least in part) by our practical goals and concerns.

If this is right, moreover, then one thing to take from the discussion so far is that practicalism is arguably not best thought of as a heresy, but rather as a kind of discovery or clarification-that is, as a kind of discovery about the sorts of factors that help to determine how much evidence, safety, etc., is required for a belief to amount to knowledge; in other words, a discovery about the sorts of factors that determine how the various thresholds relevant to knowledge are actually set.

All that said, it is clear that there are a significant number of philosophers who think otherwise. For them, the idea that practical stakes might influence whether someone knows represents a huge break with the traditional way of thinking about the nature of knowledge. It seems to bear the marks, among other things, of discredited Pascalian ideas to the effect that whether one knows (or has a belief that is justified in a knowledge-oriented way) can turn on something other than the quality of one's evidence-thus the widespread talk of 'pragmatic encroachment' in epistemology, where the language of 'encroachment' is 
obviously meant to suggest both a new, as well as an unwelcome, way of thinking about knowledge.

Although I think this resistance can be traced to a failure to distinguish between the various ways in which a belief might 'fare well' with respect to practical factors, in the remainder of this paper I will in any case shift gears and argue that even if, as an empirical matter, threshold intellectualism has enjoyed (if only implicitly) the status of orthodoxy among epistemologists, it is a piece of orthodoxy that deserves to be rejected. Since it will only be the threshold version of intellectualism that will be at issue in what follows, when I speak of 'intellectualism' from now on it will be the threshold thesis rather than the realizer thesis that I have in mind.

\section{Objections to Intellectualism}

In this section I will consider three main objections to intellectualism. ${ }^{25}$ Although I think the first objection ultimately does not have legs, it is worth considering both for the further light it helps to shed on these questions as well as for the way in which it sets the stage for the second and third objection, which (by my lights) spell real trouble for intellectualism.

On the first objection, intellectualism should be rejected because it rests on the mistaken idea that we have any 'purely epistemic goals and concerns' in the first place. According to philosophers such as Stephen Stich and Hilary Kornblith, for example, although little needs to be said on behalf of the idea that we desire certain practical goods for their own sakes, there seems to be no good reason to think that we desire anything for its

25 Or, perhaps better put, I will consider what I take to be three new objections to intellectualism. As I noted earlier, since I basically accept the practicalist interpretation of the bank cases offered by Stanley, Fantl, and McGrath, I think these cases offer a further reason for rejecting (threshold) intellectualism. 
own sake 'from a purely epistemic point of view'. ${ }^{26}$ In comparison with other goods that we obviously desire for their own sakes, the notion of a purely epistemic good should therefore strike us as little more than a fiction.

Although one thing this objection has going for it is that our grip on what it means to value something from ‘a practical point of view' seems significantly stronger than our grip on what it means to value something from a purely epistemic point of view, there nonetheless seem to be enough plausible examples of 'purely epistemic concerns' to make this sort of worry unpersuasive. It is a commonplace among scientists, for example, that certain questions are pursued simply for their own sakes, or from a pure desire to know. Indeed, whole fields of science, such as cosmology, seem to be driven precisely by such a 'pure' desire. ${ }^{27}$ Even if no practical benefit were to emerge from such research, it is often said, the research would be worth pursuing simply because it addresses questions of fundamental interest and importance. And of course there is a long tradition in philosophy of claming that philosophical questions are worth pursuing simply for their own sake-to the point where Aristotle could claim that it was precisely the practical uselessness of philosophy that made it so fine and impressive.

But even if we grant that certain questions are in fact pursued simply for their own sakes, and hence that we have certain 'purely epistemic goals and concerns,' what the Stich/Kornblith concern helps to highlight is that the sorts of goals and concerns that plausibly qualify as 'purely epistemic' are much more rarified and limited than we might originally have thought. For notice: even if we allow that certain questions or topics are

\footnotetext{
${ }^{26}$ According to Stich (1990, p. 131), for example, although we value many things intrinsically-health, happiness, the welfare of our children, etc. - the truth (Stich's main candidate for a 'purely' epistemic good) is not one of them. Similarly, although Kornblith (1993; 2003, ch. 5) is critical of many aspects of Stich's view, he seems to agree that epistemic goods are not among the things that we desire for their own sake; rather, we value having beliefs that are true (for example) because having true beliefs allows us to pursue our practical goals more effectively.

${ }_{27}$ Michael Lynch makes the same point about pure mathematics (see Lynch 2004, pp. 15-16).
} 
pursued simply for their own sakes, and from a purely epistemic point of view, it hardly seems to be the case that just any question or topic is taken to be similarly worth pursuing, from such a point of view. Thus, as Alvin Goldman has argued, although finding out the truth with respect the cause of the dinosaur extinction might seem to be something we care about from a purely epistemic point of view, the same can hardly be said for finding out the truth with respect to (say) the 323rd entry in the Wichita phone directory, or the sixth place finisher in the women's breast stroke in the 1976 Summer Olympics, or the full name of Domenico Scarlatti's maternal grandmother (etc.). ${ }^{28}$

The problem for the intellectualist, however, is that judgments about whether a particular belief amounts to knowledge are clearly not out of place when it comes to such questions, even where there seems to be no 'purely epistemic goal or concern' on the scene. Thus just as we can evaluate whether a cosmologist's beliefs amount to knowledge-a case where there seems to be a 'purely epistemic goal or concern' at stake-so too can we evaluate whether a phone book belief (say) amounts to knowledge, even though this seems to be a paradigmatic case of an epistemically trivial truth. A lucky guess that such-and-such is the $323^{\text {rd }}$ entry in the Wichita phone directory will therefore not amount to knowledge in essentially the same way that a lucky guess about some topic in cosmology will not amount to knowledge. To know in both cases, a more substantial connection to the truth is required.

We might think of this second problem for intellectualism as 'the problem of epistemically unimportant truths'-where the problem is one of explaining how the thresholds relevant to knowledge are set when it comes to what seem to be clear cases of epistemically unimportant truths (or, perhaps better, of epistemically unimportant topics or

28 These examples of 'trivial truths' are from Goldman (1999, p. 88); for the dinosaur example, see Goldman (1999, p. 3). William Alston likewise argues that since the true beliefs that we could gain from activities like memorizing phone books apparently lack epistemic value, we need to restrict the realm of those things with epistemic value to truths concerning 'matters that are of interest or importance to us' (Alston 2005, p. 32). See also Kelly (2003, pp. 624-25). 
subjects). Since it is hard to see how intellectualism can deal with this problem, it is a serious strike against the view.

Of course, one way to reply to this problem would be to say that, contrary to appearances, finding out (say) the phone number of some random person in Wichita really does correspond to some purely epistemic goal of ours-if only of a pro tanto, easily overridable sort. ${ }^{29}$ But it should be clear that this is a hard thesis to accept: even had we world enough and time, this does not seem to be the sort of truth that would be worth possessing for its own sake, even (or perhaps especially) from a purely epistemic point of view. Another, perhaps more serious, concern is that this objection might seem to prove too much. In particular, it might be thought that if this objection is a problem for intellectualism, then it is a problem for the practicalist alternative as well. After all, just as it is easy enough to find topics that are unimportant to us from a purely epistemic point of view, so too it seems easy enough to find topics that are practically unimportant as well. We need only think of the same random phone number from Wichita: just as finding out the truth with respect to this number seems to hold no value from an epistemic point of view, so too it seems to hold no value from a practical point of view. But if it holds no value from a practical point of view, then once again it is hard to see how practical values (or, practical goals and concerns) might be at work in determining whether a true belief about the Wichita phone number (say) amounts to knowledge.

Although I treat this concern at further length elsewhere, ${ }^{30}$ here I will simply note that one advantage that practicalism seems to enjoy over intellectualism in this respect is that our practical goals and concerns appear to be much more open-ended and plastic than our 'purely epistemic' goals and concerns. Thus while $I$ presently do not have a practical

\footnotetext{
29 See, for example, Kvanvig (2003, p. 41) and Lynch (2004, pp. 50-55).

30 See Grimm (manuscript).
} 
interest in the Wichita number, it is easy enough to imagine circumstances where someone might have such an interest-most obviously, if someone wanted to phone the person up, or perhaps if someone wanted to win a bet about the number, and so on. The important thing to see for our purposes, in any case, is that to the extent that someone might actually be interested enough in the number to form a belief about it, the interest here would presumably be thoroughly practical. To suppose that someone might come to be interested in the truth about the number 'simply for its own sake,' or 'from a purely epistemic point of view,' seems incredible.

The basic strategy for the practicalist, then, is clear enough: namely, to exploit the fact that many-presumably most-of our beliefs are formed with respect to topics that seem to be of only practical interest or concern to us, if they are of any concern at all. The practicalist therefore seems to be in a much better position than the intellectualist to explain how the thresholds relevant to knowledge are set across the full range of our knowledge evaluations, rather than simply with respect to some particular class of subjects (e.g. cosmology or philosophy or the like) that seem to be connected to our 'purely epistemic goals and concerns'.

The third objection to intellectualism turns on the fact that our commonsense conception of knowledge is a fallibilist one; that is, on our commonsense conception of knowledge it seems possible to know that $\mathrm{p}$ even though our evidence for $\mathrm{p}$ fails to entail the truth of $\mathrm{p}$. This spells trouble for intellectualism, however, because there is reason to think that focusing solely on our purely epistemic goals and concerns leads not to a fallibilist conception of knowledge but an infallibilist one. Put another way, there is reason to think that once our practical goals and concerns are taken out of the equation of what it takes to know, the thresholds relevant to knowledge will then become implausibly high. 
The sort of argument I have in mind here has been made in a particularly persuasive way by Bernard Williams in his Descartes: the Project of Pure Enquiry. Although some of the points Williams has to make here are peculiar to Descartes, his general remarksespecially about relationship between knowledge, practical interests, and the goals of inquiry-would seem to apply much more broadly.

According to Williams, one of the decisive moves in the Meditations comes early on, with Descartes's decision to bracket consideration of his practical goals and concerns and to focus his attention instead solely his 'purely epistemic' goals and concerns-especially, and at least to begin with, his purely epistemic goal of acquiring the truth with respect to certain questions (Williams 1978, pp. 35-37). But while an inquirer like Descartes might begin with the 'pure' goal of acquiring the truth with respect to certain questions, as Williams points out it soon becomes clear that the only way to realize this goal is by employing methods that are taken to be reliable guides on the question. As Williams puts it, since we live in a nonmagical world, a desire for the truth will not automatically lead to the truth being inscribed upon our minds (p. 40); we will therefore need to adopt a method, or a means, or acquiring the truth. And this would seem to hold, as Williams notes, not just for Descartes but for any inquirer.

But how reliable do our methods need to be, in order for the resulting (true) belief to amount to knowledge? In our everyday lives, according to Williams, for a true belief to amount to knowledge our methods need to be reliable 'enough' given the complicated array of concerns that we normally need to balance-for example, given the fact that there is often a need to act on the question at issue, or given that the resources we can devote to inquiry are limited, or given that others inquirers are depending on us as part of an epistemic division of labor, and so on (p. 46). 
According to Williams, however, Descartes upended this usual way of thinking when he explicitly decided to set his practical interests and concerns to one side to focus instead (and exclusively) on his 'purely epistemic' interests and concerns.

Descartes very carefully presents himself as now in a situation where he is devoted solely to inquiry, and to having, so long as the exercise lasts, no other interests. He stresses repeatedly... that his 'Doubt,' his instrument of reflective inquiry, is not to be brought into practical matters: equally, no values drawn from those matters affect the inquiry. The strategic rationality which guides the inquiry is to be entirely internal to it: no questions about what, in a general economic sense, is worth inquiring into or checking, are, within the confines of inquiry, to count.... With the exercise defined in these terms, then, so long as one remains within it, most the considerations that rationally weigh with [the] everyday [inquirer] against his trying to raise his truth-ratio, merely lapse. (pp. 46-47)

As Williams explains, moreover, once Descartes bracketed his practical goals and concerns, then what it took for a belief to amount to knowledge became markedly more demanding.

What is needed [to pursue the project of pure inquiry] is an error-proof method that is epistemically effective. This comes to the requirement that the beliefs which the method generates should be certain. At this point we can say that the search for truth, which is also (as we have seen) the search for knowledge, has turned into the search for certainty. It has done so because the pursuit of certainty is the only possible road for the pure search for truth, the project of improving the truth-ratio which is not constrained by any other limitations at all. (pp. 48-49)

Here is one way, then, of glossing Williams's claims: in normal cases of inquiry we naturally take into account our practical goals and concerns when we are judging not only whether inquiry has been brought to a satisfactory end, but also whether knowledge has been achieved. When these practical interests are taken out of the equation, however, then both what it takes for inquiry to be brought to a satisfactory end as well as what it takes for a belief to amount to knowledge become much more demanding. Absent these constraints, only perfectly reliable sources of belief, or only evidence that entails the truth of the belief in question, will count as 'good enough'.

With these remarks as background, we can now put our third objection to intellectualism as a kind of reductio. Suppose the thresholds relevant to knowledge are 
determined exclusively by our purely epistemic goals and concerns. In that case, then there will be unchecked pressure to ensure not just that the sources of our beliefs are reliable 'enough' given our various concerns (including our practical concerns) but that they are perfectly reliable. But the thresholds relevant to knowledge do not require perfect reliability; we normally, and legitimately, suppose beliefs can amount to knowledge even when the relevant evidence is compatible with the falsity of the beliefs. So not only should we reject the original assumption, but we should also, it seems, recognize that what helps to keep the thresholds relevant to knowledge 'fallible' is the fact that our practical interests and concerns naturally moderate our everyday judgments about what it takes to know.

Now, the intellectualist could reply to this argument in two main ways: either by denying fallibilism (and hence our normal practice of knowledge evaluation) or by denying that intellectualism entails an infallibilist account of the thresholds relevant to knowledge. Since I take it that denying fallibilism would not be an attractive option to most intellectualists, we can focus instead on the second response. What should we make of it? The basic problem with this response is that, while a case can be made in favor of requiring infallibility if only 'purely epistemic goals and concerns' are at issue (the Cartesian case as described by Williams, for example), there seems to be no principled, non-arbitrary intellectualist reason for requiring some level short of infallibility. From a 'purely epistemic' point of view, after all, why settle for $92 \%$ reliability rather than $100 \%$ ? For that matter, why settle for one non-infallible threshold rather than another: say, $92 \%$ rather than $95 \%$ reliability? ${ }^{31}$ Generalizing, we can think of the first of these questions as the 'Why anything less than perfect reliability?' question and the second as 'Why one level of imperfect

${ }^{31}$ This complaint is therefore reminiscent of BonJour's complaint cited earlier (see footnote 15). Further versions of this criticism can be found in Fantl and McGrath (forthcoming) and Pace (forthcoming). 
reliability rather than another?' question. Since it is hard to see how the intellectualist might even begin to answer these questions, this is once again a serious problem for the view. ${ }^{2}$

It is worth noting again, however, that this criticism might be thought to prove too much, because it might not be clear how the practicalist could go about answering these questions as well. But even though the debate here is ongoing, in contrast to intellectualism there at least seem to be a few plausible practicalist stories to tell. For example, along with Hawthorne, Stanley, Fantl, and McGrath, one might appeal to the ways in which our concept of knowledge seems closely tied to action. ${ }^{33}$ Roughly speaking, on this way of thinking a belief will amount to knowledge just in case we judge that it is reasonable to act on the belief-where we judge that it is reasonable to act on a belief, roughly, just in case we think that the possibility that our actions will end in failure is remote. Less than perfect reliability will therefore often be reliability 'enough,' on this view, because we often need to act under conditions of uncertainty, and just how remote the possibility of failure needs to be will depend on the cost of being wrong. Alternatively, one might draw on Edward Craig's (1990) thought that our concept of knowledge evolved to help us to flag good sources of information. On this view, a source of information need not be perfect in order to qualify as 'good' but rather simply 'good enough'-where the 'good enough' will be tied to the full range of our interests and concerns, including our practical interests and concerns. 34

\footnotetext{
${ }^{2}$ As an anonymous referee points out, one option for the intellectualist here is to reject the demand for explanation altogether. If these are in fact our 'purely epistemic goals,' and our goals are what set the standard, then it might be replied that there is simply no rational pressure on the intellectualist to look for a deeper explanation or reason for these goals. It seems to me that while this is a reasonable response, it turns on the difficult question of just which sorts of facts require an explanation, and where one can instead be satisfied with bruteness. Although I think that some sort of reason is needed for why one level of reliability (say) is required rather than another, I am willing to grant that there is no rational requirement here that the intellectualist accept this demand (request?) for an explanation. For more on this question of the need for explanation, see Grimm (2008a; 2008b).

33 See, for example, Hawthorne and Stanley (2008), and Fantl and McGrath (2008 and forthcoming). For critical discussion, see Brown (2008).

34 For examples of 'Craigian' responses along these lines, see Weinberg (2006), Henderson (2009), and Kusch (2009).
} 
While it is obvious that filling out the details of both of these stories will require further work, they nonetheless seem to offer plausible ways forward for the practicalist. For the intellectualist, there seem to be no similarly promising ways to address the two questions mentioned a moment ago.

\section{Conclusion}

In drawing to a close, it is worth emphasizing something that might have been lost in my various critical comments about the 'purely epistemic': namely, that practicalism does not deny that we have any purely epistemic goals and concerns, or that these might bear on the thresholds relevant to knowledge. Practicalism only says that the thresholds relevant to knowledge are not determined exclusively by these concerns, and that our practical goals and concerns can also bear on where the thresholds are set. In this sense, intellectualism is the stronger thesis because the more demanding, exclusive one. Practicalism, by comparison, should come across as the more expansive, hybrid theory, one that claims that the full range of our interests and concerns can influence what it takes to know.

It is also worth noting that even though I have argued that practicalism has the upper hand with respect to the objections mentioned in the previous sections, there are serious problems that seem specific to practicalism. For one thing, practicalism seems to predict, absurdly, that because thresholds are sensitive to practical stakes, you can know more by caring less. 35 For another thing, practicalism seems to be in disarray about whose practical stakes matter when it comes to our judgments about knowledge. Is it the subject? The attributor? Someone else? Since all of the extant theories apparently need to turn errortheoretic to explain away certain problem cases, perhaps the best move would be to turn

35 For versions of this criticism see, for example, Schaffer (2006), Cappelen and Lepore (2006, pp. 10441045), Schiffer (2007, pp. 194-95), Zagzebski (2009, ch. 2), and Reed (forthcoming). 
error-theoretic at the beginning and to deny the initial judgments about the bank cases etc. that fueled the support for practicalism to begin with.

Although any complete theory would have to show how these two problems might be addressed, I will not offer such an attempt here. ${ }^{36}$ What I have tried to do instead is to clarify the intellectualist/practicalist debate in epistemology, and to show that the core practicalist target (i.e. threshold intellectualism), once properly isolated and articulated, is a view that faces considerable problems. 37

Philosophy Department

STEPHEN R. GRIMM

Fordham University

Bronx, NY 10458

sgrimm@fordham.edu

\section{Works Cited}

Alston, William 2005: Beyond Justification: Dimensions of Epistemic Evaluation. Ithaca: Cornell University Press.

J. L. Austin 1946: 'Other Minds', in his 1961, pp. 44-84. Proceedings of the Aristotelian Society Supplementary Volume 20.

----- 1961: Philosophical Papers. Oxford: Clarendon Press.

BonJour, Laurence 2002: Epistemology. Lanham: Rowman \& Littlefield.

Brown, Jessica 2008: 'Knowledge and Practical Reason'. Philosophy Compass, 3, pp. 113552.

Cappelen, Herman and Ernest Lepore 2006: 'Shared Content'. In Lepore and Smith 2006, pp. 1020-55.

Clifford, W.C.K. 1879: 'The Ethics of Belief'. In his Lectures and Essays. London: MacMillan, pp. 177-211.

Cohen, Stewart 1988: 'How to be a Fallibilist'. Philosophical Perspectives, 9, pp. 91-123.

----- 1999: ‘Contextualism, Skepticism, and the Structure of Reasons’. Philosophical

${ }^{36}$ For more on these two problems, see Grimm (manuscript).

37 Thanks to Robert Audi, Jason Baehr, Selim Berker, Michael DePaul, Trent Dougherty, Jeremy Fantl, Bryan Frances, John Greco, Jonathan Kvanvig, Matt McGrath, Josh Orozco, Michael Pace, Duncan Pritchard, Declan Smithies, Ernest Sosa, John Turri, Linda Zagzebski, and the Editor of Mind for helpful comments on earlier versions of this paper. 
Perspectives, 13, pp. 57-89.

----- 2008: 'Ascriber Contextualism'. In Greco 2008, pp. 415-36.

Collins, John, Ned Hall, and Laurie Paul (eds.) 2004: Causation and Counterfactuals. Cambridge, MA: MIT Press.

Conee, Earl, and Feldman, Richard 2004: 'Afterword to Evidentialism'. In their Evidentialism: Essays in Epistemology. New York: Oxford University Press, pp. 101108.

Craig, Edward 1990: Knowledge and the State of Nature. Oxford: Clarendon Press.

DeRose, Keith 1992: 'Contextualism and Knowledge Attributions'. Philosophy and Phenomenological Research, 52, pp. 913-29.

Fantl, Jeremy, and Matthew McGrath 2002: 'Evidence, Pragmatics, and Justification'. Philosophical Review, 111, pp. 67-94.

----- 2007: 'On Pragmatic Encroachment in Epistemology'. Philosophy and Phenomenological Research, 75, pp. 558-89.

----- forthcoming: Knowledge in an Uncertain World. New York: Oxford University Press.

Goldman, Alvin 1999: Knowledge in a Social World. New York: Oxford University Press.

Greco, John (ed.) 2008: The Oxford Handbook of Skepticism. New York: Oxford University Press.

Grimm, Stephen 2008a: ‘Epistemic Goals and Epistemic Values'. Philosophy and Phenomenological Research, 77, pp. 725-44.

----- 2008b. 'Explanatory Inquiry and The Need for Explanation'. The British Journal for the Philosophy of Science, 59, pp. 481-97.

----- 2009: 'Epistemic Normativity'. In Haddock, Millar, and Pritchard 2009, pp. 243-64.

----- manuscript: “Knowledge, Practical Interests, and Rising Tides.'

Haddock, Adrian, Allan Millar, and Duncan Pritchard (eds.) 2009: Epistemic Value. New York: Oxford University Press.

Hawthorne, John 2004: Knowledge and Lotteries. New York: Oxford University Press.

Hawthorne, John, and Jason Stanley 2008: 'Knowledge and Action'. Journal of Philosophy, 105, pp. 571-90.

Hazlett, Allan 2009: 'Knowledge and Conversation'. Philosophy and Phenomenological Research, 78, pp. 591-620. 
Henderson, David 2009: 'Motivated Contextualism'. Philosophical Studies, 142, pp. 119-131.

Hetherington, Stephen (ed.) 2006: Epistemology Futures. New York: Oxford University Press.

Hookway, Christopher 1990: Scepticism. New York: Routledge.

Kelly, Thomas 2003: 'Epistemic Rationality as Instrumental Rationality: A Critique'. Philosophy and Phenomenological Research, 66, pp. 612-40.

Kornblith, Hilary 1993: 'Epistemic Normativity'. Synthese, 94, pp. 357-76.

----- 2003: Knowledge and its Place in Nature. New York: Oxford University Press.

Kusch, Martin 2009: 'Testimony and the Value of Knowledge'. In Haddock, Millar, and Pritchard 2009, pp. 60-94.

Kvanvig, Jonathan 2003: The Value of Knowledge and the Pursuit of Understanding. New York: Cambridge University Press.

----- 2008: 'Pointless Truth'. Midwest Studies in Philosophy, 32, pp. 199-212.

----- 2009: 'Responses to Critics'. In Haddock, Millar, and Pritchard 2009, pp. 339-51.

Lepore, Ernest and Barry Smith (eds.) 2006: The Oxford Handbook of Philosophy of Language. New York: Oxford University Press.

Locke, John 1689: An Essay Concerning Human Understanding. Ed. Paul Nidditch. New York: Oxford University Press.

Lynch, Michael 2004: True to Life: Why Truth Matters. Cambridge, MA: MIT Press.

Menzies, Peter 2004: 'Difference-Making in Context'. In J. Collins, N. Hall, and L. Paul 2004, pp. 139-80.

Owens, David 2000: Reason without Freedom: The Problem of Epistemic Normativity. New York: Routledge.

Pace, Michael forthcoming: 'The Epistemic Value of Moral Considerations: Justification, Moral Encroachment, and James's "Will to Believe"'. Forthcoming in Noûs.

Pritchard, Duncan 2006: Review of Jason Stanley: Knowledge and Practical Interests. Notre Dame Philosophical Reviews.

Reed, Baron forthcoming: ‘A Defense of Stable Invariantism’. Forthcoming in Noûs.

Rysiew, Patrick 2001: 'The Context-Sensitivity of Knowledge Attributions'. Noûs, 35, pp. 477-514. 
Schaffer, Jonathan 2006: 'The Irrelevance of the Subject: Against Subject-Sensitive Invariantism'. Philosophical Studies, 127, pp. 87-107.

Schiffer, Stephen 2007: 'Interest-Relative Invariantism'. Philosophy and Phenomenological Research, 75, pp. 188-95.

Sosa, Ernest 2000: 'Skepticism and Contextualism'. Philosophical Issues, 10, pp. 1-18.

Stanley, Jason 2005: Knowledge and Practical Interests. New York: Oxford University Press.

Stich, Stephen 1990: The Fragmentation of Reason: Preface to a Pragmatic Theory of Cognitive Evaluation. Cambridge, MA: MIT Press.

Turri, John 2010: 'Epistemic Invariantism and Speech Act Contextualism'. The Philosophical Review, 119, 77-95.

Weinberg, Jonathan 2006: 'What's Epistemology For? The Case for Neopragmatism in Normative Metaepistemology'. In Hetherington 2006, pp. 26-47.

Williams, Bernard 1978: Descartes: The Project of Pure Enquiry. New York: Viking Penguin.

Zagzebski, Linda 2009: On Epistemology. New York: Wadsworth. 